\title{
Management of central nervous system demyelinating diseases during the coronavirus disease 2019 pandemic: a practical approach
}

\author{
Manejo de doenças desmielinizantes do sistema nervoso central na pandemia de doença \\ do coronavírus 2019: uma abordagem prática
}

\begin{abstract}
Samira Luisa APÓSTOLOS-PEREIRA', Guilherme Diogo SILVA', Caio César Diniz DISSEROL', Lucas Bueno FEO', Aline de Moura Brasil MATOS', Vinicius Andreoli SCHOEPS', Ana Beatriz Ayroza Galvão Ribeiro GOMES', Mateus BOAVENTURA', Maria Fernanda MENDES ${ }^{1,2}$, Dagoberto CALLEGARO'1
\end{abstract}

\begin{abstract}
Background:The novelcoronavirus disease 2019 (COVID-19) pandemic poses a potentialthreat to patientswith autoimmune disorders, including multiple sclerosis (MS) and neuromyelitis optica spectrum disorder (NMOSD). Such patients are usually treated with immunomodulatory or immunosuppressive agents, which may tamper with the organism's normal response to infections. Currently, no consensus has been reached on how to manage MS and NMOSD patients during the pandemic. Objective: To discuss strategies to manage those patients. Methods: We focus on how to 1) reduce COVID-19 infection risk, such as social distancing, telemedicine, and wider interval between laboratory testing/imaging; 2) manage relapses, such as avoiding treatment of mild relapse and using oral steroids; 3) manage disease-modifying therapies, such as preference for drugs associated with lower infection risk (interferons, glatiramer, teriflunomide, and natalizumab) and extended-interval dosing of natalizumab, when safe; 4 ) individualize the chosen MS induction-therapy (anti-CD20 monoclonal antibodies, alemtuzumab, and cladribine); 5) manage NMOSD preventive therapies, including initial therapy selection and current treatment maintenance; 6) manage MS/ NMOSD patients infected with COVID-19. Conclusions: In the future, real-world case series of MS/NMOSD patients infected with COVID-19 will help us define the best management strategies. For the time being, we rely on expert experience and guidance.
\end{abstract}

Keywords: Multiple Sclerosis; Neuromyelitis Optica Spectrum Disorders; Coronavirus; Immunosuppressive Agents; Drug Side Effects.

\begin{abstract}
RESUMO
Introdução: A mais recente pandemia causada pelo coronavírus SARS-CoV-2 (COVID-19, do inglês coronavirus disease 2019) representa uma ameaça potencial para pacientes com doenças autoimunes, incluindo esclerose múltipla (EM) e transtorno do espectro de neuromielite óptica (NMOSD, do inglês neuromyelitis optica spectrum disorders). Esses pacientes são geralmente tratados com medicamentos imunomoduladores ou imunossupressores que podem alterar a resposta normal do organismo a infecções. Até o momento, não há consenso sobre como o manejo dos pacientes com EM e NMOSD deve ser realizado durante a pandemia. Objetivo: Discutir estratégias para manejar esses pacientes. Métodos: Focamos em como 1) reduzir o risco de infecção por COVID-19, como distanciamento social, telemedicina e exames laboratoriais e de imagem em intervalos mais amplos; 2) manejo de surtos, incluindo evitar tratamento de surto leve e uso de corticoide oral; 3) gerenciar terapias modificadoras de doença, como a preferência por medicamentos associados a menor risco de infecção (interferons, glatirâmer, teriflunomida e natalizumabe) e infusão em intervalo estendido de natalizumabe, quando seguro; 4) individualizar a escolha da terapia de indução para EM (anticorpos monoclonais anti-CD20, alentuzumabe e cladribina); 5) manejar terapias preventivas de NMOSD, incluindo seleção inicial de terapia e manutenção do tratamento atual; 6) manejar pacientes com EM/NMOSD que foram infectados por COVID-19. Conclusão: No futuro, séries de casos de pacientes com MS/NMOSD infectados com COVID-19 nos ajudará a definir as melhores estratégias de manejo. Por enquanto, contamos com a experiência e orientação especializadas.
\end{abstract}

Palavras-chave: Esclerose Múltipla; Neuromielite Óptica; Coronavírus; Imunossupressor; Efeitos Colaterais e Reações Adversas Relacionados a Medicamentos.

\footnotetext{
'Universidade de São Paulo, Hospital das Clínicas, School of Medicine, Department of Neurology, São Paulo SP, Brazil.

${ }^{2}$ Santa Casa de São Paulo, School of Medical Sciences, Department of Neurology, São Paulo SP, Brazil.

Samira Luisa APÓSTOLOS-PEREIRA (D) https://orcid.org/0000-0003-0560-6901; Guilherme Diogo SILVA (DD https://orcid.org/0000-0001-9764-3763; Caio César Diniz DISSEROL (DD https://orcid.org/0000-0001-7568-0897; Lucas Bueno FEO (D) https://orcid.org/0000-0002-4679-9765;

Aline de Moura Brasil MATOS (DD https://orcid.org/0000-0002-1854-2575; Vinicius Andreoli SCHOEPS (D) https://orcid.org/0000-0001-8875-0567;

Ana Beatriz Ayroza Galvão Ribeiro GOMES (D) https://orcid.org/0000-0003-1657-6891; Mateus BOAVENTURA (DD https://orcid.org/0000-0002-5914-8099;

Maria Fernanda MENDES (D) https://orcid.org/0000-0003-3983-6019; Dagoberto CALLEGARO (D) https://orcid.org/0000-0003-0077-173X

Correspondence: Samira Luisa Pereira Apóstolos; E-mail: samira.apostolos.neuro@gmail.com

Conflict of interests: The authors Samira Luisa Apóstolos Pereira, Maria Fernanda Mendes, and Dagoberto Callegaro have participated in the production of presentations and material for Biogen, Merck, Novartis, and Sanofi-Genzyme.

Authors' contributions: SLPA and MFM: Substantial contributions to the study design and development, writing of the article, and critical revision. GDS, CCDD, LBF, AMBM, VAS, ABAGRG, and MB: Substantial contributions to the study design and development. DC: Substantial contributions to the approval of the final version.

Received on April 28, 2020; Received in its final form on May 23, 2020; Accepted on May 31, 2020.
} 


\section{INTRODUCTION}

The coronavirus disease 2019 (COVID-19) pandemic is the latest threat to global health. It is a fast-spreading respiratory infection caused by a novel coronavirus identified in December 2019. As it can evolve to severe acute respiratory syndrome (SARS) and has a high transmission rate (on average, each infected person spreads the virus to another two people), it poses a challenge to public health and clinical practice. The pandemic is not expected to end for at least 18 months $^{1}$. During this time, management of chronic autoimmune diseases will be a challenge.

The coronavirus family shows a potential neurotropism that may induce neurological disorders, such as inflammatory polyneuropathy, encephalopathy, ischemic stroke, and demyelinating diseases. Neurotropism can occur via translamina cribrosa with SARS-CoV-2 penetrating the central nervous system (CNS) through the olfactory tract. Interaction with human cells probably starts with the bond between the S1 portion of the virus S protein and the host angiotensinconverting enzyme (ACE) type 2 receptors ${ }^{2}$. Those receptors are widespread in the human body and the CNS, as they are present in endothelial and arterial smooth muscle cells ${ }^{3}$. Endothelial dysfunction and consequent blood-brain barrier disruption may work as an entry door for infected leukocytes into the CNS. This scenario might lead to direct viral damage to the parenchyma, as observed with other viruses, or trigger clinical events associated with CNS autoimmune disorders.

Multiple sclerosis (MS) is a chronic, demyelinating, autoimmune disease of the $\mathrm{CNS}^{4}$. It is the most common demyelinating disease and the main cause of neurological disability in young adults following trauma ${ }^{5}$. Neuromyelitis optica spectrum disorder (NMOSD) - differential diagnosis of MS - is a group of recurrent autoimmune diseases of the CNS that classically affects the optic nerves and spinal cord ${ }^{6}$. It is associated with the presence of antibodies against aquaporin-4 (AQP4-IgG) water channel in more than $70 \%$ of cases ${ }^{7}$. AQP4-IgG seronegative NMOSD comprises a heterogeneous group of both monophasic and relapsing inflammatory CNS disorders, which include diseases related to myelin oligodendrocyte glycoprotein antibodies (MOG IgG), post-infectious inflammation, and other conditions caused by unidentified antibodies $^{8,9}$. NMOSD represents approximately $20 \%$ of all demyelinating diseases of the CNS in Latin America9.

MS and NMOSD require continuous preventive treatment to avert disability and improve quality of life. There is no cure for MS or NMOSD, but the long-term prognosis for patients with both diseases improved considerably over the last decade. This situation is mainly thanks to the emergence of a highly active immunotherapeutic approach. This treatment strategy includes drugs, known as disease-modifying drugs (DMDs), that interfere with the immune system through modulating or suppressive mechanisms, which may tamper with the organism's normal response to infections.
The follow-up of patients with demyelinating disorders is complex and involves regular appointments for clinical assessment, routine CNS imaging, and laboratory monitoring, which can be perilous during a pandemic.

Currently, no consensus has been reached on how to manage MS and NMOSD patients during the pandemic. The Brazilian Committee for Treatment and Research in Multiple Sclerosis (BCTRIMS), the Latin American Committee for Treatment and Research in Multiple Sclerosis (LACTRIMS), and the European Committee for Treatment and Research in Multiple Sclerosis (ECTRIMS) have issued expert recommendations on their websites ${ }^{10,11}$. In the next few topics, we will discuss management strategies for patients with demyelinating disorders that have been adopted at two large MS/NMOSD care centers in the city of São Paulo, Brazil, during this period. We offer a practical approach aimed at mitigating COVID-19 infection risk whilst maintaining clinical stability and safety.

\section{How to monitor clinical status?}

As social distancing becomes the recommendation to avoid COVID-19 infection, new ways must be sought to achieve optimal management of patients with chronic autoimmune disorders while still maintaining efficient disease prevention. Recently, telemedicine has been adopted as a clinical management tool, which now has legal support in our country (Law no. 13,989 of April 15, 2020). Remote care has become a safe way of monitoring patients during the pandemic.

The literature regarding telemedicine and MS has been recently reviewed, highlighting benefits in several aspects involved in MS care (e.g., cost-effectiveness and satisfaction of patients and providers) $)^{12}$. This tool is supported by the Brazilian Academy of Neurology, which has recently published recommendations for conducting a remote neurological examination ${ }^{13}$. Simple approaches, such as the timed 25-foot walk, are considered feasible ways of assessing MS patients. If necessary, more complex evaluations, such as the fundoscopic examination, can also be used with proper technological support ${ }^{14}$. However, this method is not without its drawbacks, particularly concerning compliance to treatment during extended periods and technological barriers.

During the current COVID-19 pandemic, phone and/or e-mail contact have been established with most patients at both Hospital das Clínicas da Faculdade de Medicina da Universidade de São Paulo and Faculdade de Ciências Médicas da Santa Casa de São Paulo. This contact has allowed direct interaction between patient and caregiver in order to reschedule future appointments, check the results of laboratory tests and imaging, address patient's complaints, perform drug monitoring/management, and provide information concerning the pandemic. Table 1 shows recommendations for telemedicine consultations for MS/NMOSD patients during the COVID-19 pandemic. 
How to deal with relapses of demyelinating disease?

\section{Multiple sclerosis}

Relapse is a demyelinating event of the CNS lasting at least $24 \mathrm{~h}$, in the absence of fever or infection ${ }^{4}$. Thus, infection should be excluded when faced with a worsening of neurological symptoms of MS. During the pandemic, ruling out COVID-19 is reasonable. As SARS-CoV-2 has been associated with demyelinating events in case reports ${ }^{15}$ during the pandemic, COVID-19 should be ruled out for all patients with relapses. As an evaluation protocol, we suggest assessing patients for typical clinical findings (e.g., cough, fever, respiratory symptoms, hyposmia/anosmia, and hypogeusia). If present, we recommend performing chest computed tomography, SARS-CoV-2 RT-PCR, and/or immunological assays. The sensitivity of the latter may be limited in MS patients with impaired humoral responses associated with certain DMDs.

After ruling out active infection, the next management step is to classify relapse severity. For most relapses, consensus treatment consists of $1000 \mathrm{mg}$ intravenous infusion of methylprednisolone for 3-5 days. However, at least for optic neuritis $(\mathrm{ON})$, this treatment has proven to speed neurological recovery with no impact on long-term disability ${ }^{16}$. Hence, we suggest avoiding corticosteroids for the treatment

Table 1. Telemedicine approach for multiple sclerosis/ neuromyelitis optica spectrum disorder patient care during the COVID-19 pandemic.

\begin{tabular}{ll}
\multicolumn{1}{c}{ Strategies for MS/NMOSD care } \\
\hline Education about the COVID-19 pandemic: \\
patients should be instructed - via e-mail, \\
telephone, or video-call - to: 1) follow social \\
distancing, 2) be rigorous about hand hy- \\
giene and mask use, 3) go to an emergency \\
room in the presence of red flags for severe \\
SARS-CoV-2 infection (dyspnea, fever), 4) if \\
necessary, ask for a medical report explain- \\
ing the need for home-office work and influ- \\
enza vaccination. \\
Laboratory testing: blood count and immu- \\
noglobulin levels can be checked through \\
e-mail. We suggest explaining to patients \\
that more flexible monitoring may be more \\
appropriate to reduce infection risk. \\
Magnetic resonance imaging: we recom- \\
mend annual CNS imaging (MRI) to be \\
checked via telemedicine, e-mail, or online. \\
Outpatient consultation: routine appoint- \\
ments should be rescheduled or performed \\
using telemedicine. When prescribing a \\
DMD, we should discuss drug access strat- \\
egies (e.g., family member goes to the drug- \\
store instead of the patient). \\
Emergency consultation: relapse evaluation \\
should start by excluding active infections. \\
CovID-19 should be ruled out. Neurological \\
examination and prescription of high-dose \\
oral steroids can be performed using tele- \\
medicine to prevent hospitalization.
\end{tabular}

MS/NMOSD: multiple sclerosis/neuromyelitis optica spectrum disorder. of mild outbreaks. We believe faster improvement of mild neurological symptoms does not outweigh the increased infection risk associated with the use of steroids.

While intravenous steroids are the mainstay treatment approach for MS relapses, studies have shown that relapse treatment with oral steroids can be similarly effective $e^{17,18}$. As oral corticosteroids can be administered without breaking social distancing, we believe this practice should be considered as a treatment strategy during the pandemic. We propose treating relapses with custom-made oral methylprednisolone tablets at $1000 \mathrm{mg}$ per day for five days. If oral tablets are unavailable (a common situation in Brazil), we recommend the use of intravenous methylprednisolone $(1000 \mathrm{mg})$ for five days, preferably in a day hospital regimen. In the case of contraindications to high-dose steroids, intravenous immunoglobulin (total dose of $2 \mathrm{~g} / \mathrm{kg}$ administered for 2-5 days) is reasonable ${ }^{19}$.

\section{Neuromyelitis optica spectrum disorder}

We believe more caution is required when dealing with NMOSD relapses. These relapses are often more severe, steroid-refractory, and lead to greater disability than usually observed in $\mathrm{MS}^{20}$. We suggest that NMOSD patients with symptoms suggestive of relapses should be clinically assessed promptly, and usual treatment with intravenous steroids and plasmapheresis should be considered. If plasma exchange is not available, intravenous immunoglobulin may contribute to relapse treatment following incomplete response to steroid treatment ${ }^{21}$. We underline that not all relapses behave the same way. ON and longitudinally extensive transverse myelitis (LETM) relapses are usually more aggressive, and early plasma exchange is associated with better progno$\mathrm{sis}^{20}$. Area postrema syndrome (APS) relapses, for instance, are usually much more benign than other typical syndromes. Nonetheless, APS attacks may precede inflammatory involvement of optic nerves or spinal cord, making APS an important warning sign. About $80 \%$ of APS patients improve with steroids (methylprednisolone) in the first 2 days of treatment, while less than $20 \%$ of them need plasmapheresis. We advise early treatment of APS attacks, as it may not only reduce clinical severity but also prevent accompanying disabling $\mathrm{ON}$ or transverse myelitis (TM) attacks ${ }^{8,22}$.

\section{Other demyelinating diseases}

Some acute demyelinating events do not fulfill the MS or NMOSD diagnostic criteria. They include: acute disseminated encephalomyelitis (ADEM), idiopathic isolated ON, and idiopathic isolated TM. We suggest treating these events with intravenous steroids, immunoglobulin, and plasma exchange, as performed outside the pandemic context. These conditions do not usually require long-term immunotherapy9.

MOG IgG-associated optic neuritis, encephalitis, and myelitis (MONEM) may present with monophasic or recurrent course ${ }^{8}$. MOG IgG disease relapses usually show a 
favorable response to steroids. In this specific situation, recurrence is associated with long-term seropositivity for MOG IgG, and immunosuppressive therapy should be discussed individually ${ }^{23}$.

\section{When to start or stop disease-modifying drugs?}

\section{Multiple sclerosis}

The best initial treatment strategy for MS (induction $\times$ escalation therapy) is still under debate. Induction therapy is the use of high-efficacy treatments, which leads to faster control of disease activity ${ }^{24}$. Contrarily, traditional escalation therapy consists of prescribing safer low-efficacy drugs, which can be later switched to more effective alternatives in the face of clinical or radiological activity. A recent observational study suggests that the first strategy may lead to lower long-term disability $^{25}$, which greatly favors this approach. However, these data still need to be replicated in experimental trials (as in the ongoing TREAT-MS and DELIVER-MS trials).

Escalation therapy may be considered for most MS patients, since more than $80 \%$ of them do not have aggressive $\mathrm{MS}^{25}$. Some DMDs used in this approach are not associated with increased risk of infection, such as beta-interferons, glatiramer acetate, and teriflunomide ${ }^{26}$. Dimethyl fumarate association with increased infection risk was controversial ${ }^{27}$. Therefore, they should be preferred for these patients during the pandemic.

Nevertheless, around $10 \%^{25}$ of MS patients present with highly active disease, and these drugs may not be adequate for them as initial therapy. Additionally, the role of each specific DMD in risk and severity of SARS-CoV-2 infection has not been established yet. Patients with high disease burden may require high-efficacy treatments. In these situations, we, as well as the ECTRIMS/Multiple Sclerosis International Federation (MSIF), recommend selecting therapies not associated with lymphopenia, such as natalizumab. Use of fingolimod, cladribine, alemtuzumab, and anti-CD20 monoclonal antibodies can lead to lymphopenia ${ }^{28}$. As they are associated with significant infection risk in real-world data, we propose an individualized risk/benefit analysis before prescribing these drugs. Moreover, in a recent pharmacovigilance series, ocrelizumab was not associated with the more severe course of COVID-1929. Therefore, ocrelizumab may be a treatment option for patients with aggressive $\mathrm{MS}^{30}$.

We do not recommend stopping DMDs for patients already under treatment. Stopping fingolimod and natalizumab is associated with rebound ${ }^{31,32}$. Rebound can lead to higher disability, hospitalization, and further immunosuppression (i.e., intravenous methylprednisolone), exposing patients to a higher risk of severe COVID-19 infection.

Currently, there is no specific advice regarding treatment for pregnant women, children, or older patients (>60 years of age) with MS during the COVID-19 pandemic. As geriatric and pregnant patients present an increased risk of severe
SARS-CoV-2 infection, and a recent meta-analysis has shown that older patients may not have an optimal response to MS treatment $^{33}$, we suggest individual risk-assessment when prescribing DMDs for pregnant and geriatric patients.

\section{Neuromyelitis optica spectrum disorder}

When untreated, approximately $50 \%$ of NMOSD patients will become wheelchair-bound and blind, and a third of them will die within 5 years of their first attack ${ }^{6}$. Hence, we strongly recommend not interrupting immunosuppressive preventive treatment in NMOSD cases. The two most common first-line treatment drugs in NMOSD are azathioprine and rituximab. We suggest rituximab as the preferred initial therapy during the pandemic because:

- Both drugs have similar risks of infection ${ }^{34}$.

- Rituximab is more effective than azathioprine in reducing relapses ${ }^{32}$.

- Rituximab requires less laboratory monitoring.

In patients with persistent MOG IgG positivity and NMOSD clinical phenotype, we propose the same management strategy, using rituximab as first-line treatment, at least during the COVID-19 pandemic context ${ }^{23}$. However, we emphasize that MONEM patients may not experience the same efficacy profile as AQP4-positive patients ${ }^{35}$.

\section{Strategies in prescribing and monitoring disease-modifying drugs}

\section{Multiple sclerosis}

Most MS DMDs require regular clinical, laboratory, and magnetic resonance imaging (MRI) monitoring to assess disease activity and drug-related side effects. Lymphopenia, as seen with the use of fingolimod, dimethyl fumarate, and antiCD20 monoclonal antibodies, poses a major concern, as it may be related to a higher incidence of infectious diseases ${ }^{36}$.

Regarding fingolimod, upper and lower respiratory tract infections are known for being more common in patients using this DMD. In the pivotal trial ${ }^{37}$, lymphopenia was frequent, and lymphocyte counts were measured monthly in the first trimester of use and every three months thereafter. Fingolimod-related lymphopenia, however, has not been associated with a higher incidence of infections ${ }^{38}$. Lymphocyte counts are not direct markers of immunosuppression because they do not reflect absolute lymphopenia but rather a redistribution of cells (lymphocyte retention in lymph nodes). From our perspective, laboratory testing should be restricted to the minimum necessary to mitigate coronavirus infection. We suggest one complete blood count $(\mathrm{CBC})$ three months after introducing the treatment and every six months thereafter, aiming to keep lymphocytes above 200 cells.

Teriflunomide is also associated with lymphopenia. Nonetheless, in a pooled analysis of TEMSO, TOWER, TOPIC, 
and TENERE, low-grade (Grade 1 or Grade 2) lymphopenia was infrequent, and no high-grade (Grade 3 or Grade 4) lymphopenia was reported. Furthermore, infection rates in patients treated with teriflunomide were similar in populations with and without low-grade lymphopenia ${ }^{39}$. We recommend performing one $\mathrm{CBC}$ three months after introducing the treatment and every six months thereafter.

Dimethyl fumarate-related persistent lymphopenia (lower than 500 lymphocytes for more than 6 months) has been associated with progressive multifocal leukoencephalopathy (PML). As the original trials used an 800 lymphocytecount as the cut-off point for significant lymphopenia and we are concerned with the risk of severe respiratory infections in addition to PML, we have adopted this cut-off point for reevaluating the DMD choice ${ }^{40}$. We suggest the same monitoring interval and telemedicine follow-up, as adopted for fingolimod and teriflunomide.

Natalizumab is associated with increased infection risk when compared to beta-interferons and glatiramer acetate. However, it has a lower infection risk than other high-efficacy therapies, such as fingolimod and anti-CD20 monoclonal antibodies ${ }^{41}$. Natalizumab has well-established safety and efficacy profile, except for the $0.7 \%$ of PML cases in reallife series ${ }^{42}$. This rare and fatal infectious demyelinating disease is caused by a polyomavirus called John Cunningham virus (JCV). PML associated with natalizumab use is a constant concern. Extended-interval dosing ${ }^{43,44}$ is a strategy that has proven, through observational data, to reduce PML risk, while maintaining treatment efficacy. It consists of a 5-8 weeks interval dosing of natalizumab instead of the standard 4 weeks (standard interval dosing). This strategy is particularly interesting in the COVID-19 pandemic setting, as it allows less exposure to viral contamination. Our current protocol involves a 6-week interval dosing for patients previously treated with the standard interval protocol and, in some cases, an 8-week interval dosing for patients previously treated with a 6-week interval.

Anti-CD20 monoclonal antibodies (ocrelizumab and off-label use of rituximab) are frequently used for the treatment of MS. Anti-CD20 monoclonal antibodies have previously been linked to an increased risk of severe viral infections, a major concern during the COVID-19 pandemic. Causal mechanisms include: neutropenia, lymphopenia, and hypogammaglobulinemia. Therefore, when prescribed, we recommend $\mathrm{CBC}$ and immunoglobulin monitoring (total serum IgA, IgM, IgG) every six months or in the case of recurrent infection. Immunoglobulin replacement in patients with hypogammaglobulinemia is associated with lower infection risk related to rituximab use. We consider this recommendation particularly important in a viral pandemic context ${ }^{45}$. CD19 monitoring may be a reasonable strategy to individualize decision making on dosage and reinfusion intervals of B-cell depleting therapies ${ }^{46}$. Nonetheless, in a recent series, ocrelizumab was not associated with severe COVID-19 $9^{29,47}$.
Thus, this treatment option seems reasonable for aggressive MS patients ${ }^{30}$ with positive JCV.

Cladribine is an immunosuppressive agent used as induction therapy in MS patients. It has a preferential lymphocyte depletion that reaches its nadir one month after the last administered dose and is further intensified after the second cycle $^{48}$. At that time, a $60 \%$ reduction in CD4 count and a $40 \%$ decrease in CD8 are expected, with relative stabilization in a year. We highlight that the degree of lymphopenia does not seem to be related to MS relapses. However, more pronounced levels (i.e., $<500$ lymphocytes $/ \mathrm{mm}^{3}$ ) have led to a two-fold increase in the incidence of Herpes-Zoster in the pivotal trial.

Alemtuzumab is an anti-CD52 monoclonal antibody induction therapy. A cycle of this drug results in $>90 \%$ depletion of both CD4 and CD8 in the first month, with gradual recovery to $70 \%$ of the baseline after a year, just before the second cycle ${ }^{49}$.

Therefore, cladribine and alemtuzumab significantly compromise immune defenses against infection. Some studies have shown that omitting a second dose of alemtuzumab may still lead to significant disease control ${ }^{50}$. Nevertheless, more data are necessary before we can affirm this omission will not compromise the long-term efficacy of the therapy.

We acknowledge that highly active MS patients may need a more aggressive approach, even when facing a higher infection risk in a pandemic. Patients who are older at symptom onset $^{25}$ (>35 years), have any pyramidal sign, and present greater disability (Expanded Disability Status Scale (EDSS) score $\geq 3.0$ ) in the first year after symptom onset are at higher risk of developing aggressive disease. Those patients represent around $10 \%$ of MS patients and deserve a very individualized and shared approach. Induction therapy may be plausible in this setting ${ }^{25}$.

Hematopoietic stem cell transplantation (HSCT) is an induction treatment for MS. It aims to stop MS damage by cell depletion and then repopulate the immune system. This treatment has a long sustained effect on the immune system. People who have recently received this treatment should extend the period of isolation during the COVID-19 outbreak. Patients who are eligible for HSCT should consult their neurologists and consider postponing the procedure. Table 2 summarizes considerations regarding DMD use for MS during the COVID-19 pandemic.

In addition, we recommend annual CNS imaging (MRI) to be checked via telemedicine for almost all stable MS patients. Natalizumab-treated patients with double or triple PML risk (combination of 2-3 of the following: previous immunosuppression, JCV index $>0.9$, or $>24$ infusions) are the exception to this recommendation. These patients require MRI monitoring for asymptomatic PML screening every 3-6 months.

\section{Neuromyelitis optica spectrum disorder}

Rituximab is frequently used for the treatment of NMOSD. Rituximab leads to an increased risk of severe 
viral infections by several mechanisms, as described above. Immunoglobulin monitoring and replacement, as appropriate, may be a strategy to reduce infection risk. Regarding B-cell monitoring in NMOSD, targeting $\mathrm{CD} 27^{+}$memory $\mathrm{B}$-cells rather than $\mathrm{CD} 19^{+} \mathrm{B}$-cells is more likely to provide a better measure of rituximab efficacy. In a study, more than half of NMOSD relapses occurred at $\mathrm{CD} 19^{+} \mathrm{B}$-cell counts below $0.01 \times 10^{9} / \mathrm{L}$ but above the therapeutic threshold for $\mathrm{CD} 27^{+}$memory B-cells. As CD27 markers are not available in clinical practice and, as in NMOSD relapses, can be fatal, we suggest continuing rituximab dosing at regular 6 months intervals ${ }^{51}$.

Chronic steroid use is a common bridge therapy for NMOSD until immunosuppressants start to be effective. Infection risk is a dose-dependent side effect of steroid use $^{52}$. Hence, we recommend steroid tapering, when safe. We have been using telemedicine as an aid for taper schedule patient guidance.

Table 2. Multiple sclerosis disease-modifying drugs and severe COVID-19 risk: recommendations on therapy initiation and maintenance.

\begin{tabular}{|c|c|}
\hline $\begin{array}{l}\text { Interferons } \\
\text { Glatiramer } \\
\text { Teriflunomide } \\
\text { (Low risk) }\end{array}$ & Safe choice for therapy initiation. \\
\hline \multirow{2}{*}{$\begin{array}{l}\text { Dimethyl } \\
\text { fumarate (Low } \\
\text { to moderate } \\
\text { risk) }\end{array}$} & $\begin{array}{l}\text { Association with increased infection risk is } \\
\text { controversial; drug initiation should be dis- } \\
\text { cussed on a case-to-case basis }\end{array}$ \\
\hline & We suggest maintenance of therapy. \\
\hline \multirow{2}{*}{$\begin{array}{l}\text { Fingolimod } \\
\text { (Moderate risk) }\end{array}$} & $\begin{array}{l}\text { Careful individualized approach should be } \\
\text { considered when starting this drug during the } \\
\text { pandemic. }\end{array}$ \\
\hline & $\begin{array}{l}\text { We suggest maintenance of therapy. } \\
\text { Lymphopenia should be monitored in a more } \\
\text { flexible interval (at } 3 \text { months of introduction and } \\
\text { every } 6 \text { months thereafter) via telemedicine. }\end{array}$ \\
\hline \multirow[b]{2}{*}{$\begin{array}{l}\text { Natalizumab } \\
\text { (Low Risk) }\end{array}$} & $\begin{array}{l}\text { Safe choice for therapy initiation in highly ac- } \\
\text { tive disease. }\end{array}$ \\
\hline & $\begin{array}{l}\text { We recommend the maintenance of natalizum- } \\
\text { ab and suggest extended-interval dosing to re- } \\
\text { duce the risk of patient exposure to COVID-19. } \\
\text { Asymptomatic PML screening should not be } \\
\text { interrupted in high-risk patients, even during } \\
\text { the pandemic. }\end{array}$ \\
\hline \multirow[b]{2}{*}{$\begin{array}{l}\text { Ocrelizumab } \\
\text { Rituximab } \\
\text { (Moderate risk) }\end{array}$} & $\begin{array}{l}\text { Careful individualized approach should be } \\
\text { considered when starting this drug during the } \\
\text { pandemic. }\end{array}$ \\
\hline & $\begin{array}{l}\text { We recommend the maintenance of anti-CD20 } \\
\text { therapy. CD19 monitoring can be considered } \\
\text { as an aid to prolong infusion interval. } \\
\text { Immunoglobulin levels should be checked and } \\
\text { replaced if needed. May be an option in ag- } \\
\text { gressive MS. }\end{array}$ \\
\hline \multirow{2}{*}{$\begin{array}{l}\text { Cladribine } \\
\text { Alemtuzumab } \\
\text { (High risk) }\end{array}$} & $\begin{array}{l}\text { Careful individualized approach should be consid- } \\
\text { ered when starting this drug during the pandemic. }\end{array}$ \\
\hline & $\begin{array}{l}\text { It is not clear if postponing the second cycle } \\
\text { may compromise treatment efficacy }\end{array}$ \\
\hline
\end{tabular}

Azathioprine is an NMOSD treatment commonly used in Brazil. Azathioprine adverse-event data from other autoimmune diseases suggest myelosuppression is more common in the first year of therapy (mean time of 8 months) ${ }^{53,54}$. Therefore, we recommend considering a longer hematological monitoring interval for patients with stable azathioprine use ( $>1$ year) to reduce coronavirus exposure risk. We propose routine laboratory testing every 6 months during the pandemic for these patients.

Mycophenolate mofetil has proven to be effective in preventing NMOSD relapses ${ }^{55}$. Its mechanism of action causes immunosuppression through cytostatic effects on $\mathrm{T}$ and B cells. Data regarding its adverse effects are mainly from transplant recipients and systemic lupus erythematosus (SLE) patient trials. Cytopenia and increased risk of bacterial and viral infections are observed among these patients $\mathrm{s}^{56,57}$. We recommend weekly $\mathrm{CBC}$ and liver enzyme monitoring during the first 4-6 weeks of treatment and every 3 months thereafter.

Methotrexate is an immunosuppressive agent occasionally used in NMOSD. At a low-dose (e.g., 7.5 to $25 \mathrm{mg}$ ), myelosuppression is infrequent, and most patients are not prone to opportunistic infections (unless under concomitant use of high-dose corticosteroids $)^{58}$. However, hepatotoxicity is common ${ }^{59}$. Pancytopenia can occur with variable therapy intervals, but predisposing factors are present in the majority of these patients (most often impaired renal function) ${ }^{60}$. Thus, during the pandemic, we suggest $\mathrm{CBC}$ and liver enzyme monitoring at a six-month interval for patients on stable doses of methotrexate without adverse events in the last six months. For patients under methotrexate $<6$ months or with a prior history of adverse events, we recommend more frequent monitoring (e.g., 2-3-month interval) ${ }^{61}$. Table 3 summarizes considerations regarding DMD use for NMOSD during the COVID-19 pandemic.

\section{How to mitigate coronavirus disease 2019 infection risk in multiple sclerosis/neuromyelitis optica spectrum disorder patients}

Most of the general population are expected to be infected by COVID-19 in the next months. Most people will

Table 3. Neuromyelitis optica spectrum disorder disease-modifying drugs and severe COVID-19 risk: recommendations on therapy initiation and maintenance.

\begin{tabular}{ll}
\hline $\begin{array}{l}\text { Rituximab } \\
\text { (Moderate risk) }\end{array}$ & $\begin{array}{l}\text { Maintain anti-CD20 therapy every } 6 \text { months. } \\
\text { Immunoglobulin levels should be checked and } \\
\text { replaced if needed. }\end{array}$ \\
& $\begin{array}{l}\text { Alternative choice for therapy initiation. } \\
\text { Azathioprine } \\
\begin{array}{l}\text { Mycophenolate } \\
\text { Moderexate }\end{array}\end{array} \begin{array}{l}\text { Laboratory testing should be performed in a } \\
\text { more flexible interval in stable patients (ev- } \\
\text { ery } 6 \text { months for patients with disease and } \\
\text { laboratory stability for at least one year) and } \\
\text { checked via telemedicine. }\end{array}$ \\
\hline
\end{tabular}


be asymptomatic or develop mild disease. In Brazil, the Ministry of Health considers the following group as high risk for severe COVID-19: people over 60 years of age, those with severe cardiac diseases, severe lung disease, kidney diseases, diabetes, under immunosuppression, and pregnant women.

MS/NMOSD patients are included in the special population with higher risk of severe infection, according to the Brazilian government. Nevertheless, currently, there is no clear evidence that MS/NMOSD infected patients present a higher risk of life-threatening SARS-CoV-2 disease. The Brazilian Academy of Neurology is developing a national database with MS patients infected with SARS-CoV-2 to investigate this risk in our country ${ }^{62}$. In the Italian case series of $232 \mathrm{MS}$ patients who acquired SARS-CoV-2 infection, $96 \%$ of them presented mild disease. Only five patients died $(2 \%)^{47}$. Four out of these five patients presented significant comorbidities (e.g., hypertension, diabetes, cerebrovascular and cardiac diseases), and their mean age was 66.8 (54-82) years $^{47}$.

In addition to social distancing, we believe certain measures may lead to infection prophylaxis. Vaccination should be administered to mitigate infection risk in immunosuppressed/immunomodulated patients whenever possible. Vaccination schedule suggestions for patients with demyelinating diseases have been previously published ${ }^{63}$. In general, the same principles adopted for patients with systemic autoimmune diseases are followed, such as avoiding live virus/bacterial vaccines ${ }^{64,65,66}$. We underline that vaccine effectiveness may be compromised in patients under certain disease-modifying therapies (DMTs), such as fingolimod, anti-CD20 monoclonal antibodies, natalizumab, alemtuzumab, and cladribine.

During the current pandemic, patients with demyelinating diseases should be vaccinated against influenza, as this respiratory virus can coinfect patients and lead to severe clinical symptoms. As response to the pneumococcal vaccine is severely impaired when associated with the use of antiCD20 monoclonal antibodies ${ }^{67,68}$, we recommend all patients receive pneumococcal vaccination 2-3 weeks prior therapy initiation in a stepwise schedule (i.e., PCV13 prime followed by PPSV23 boost), with an interval of at least 8 weeks between the two vaccinations ${ }^{64,65}$. In patients receiving antiCD20 therapies, vaccination must start at least 2-3 weeks before treatment or 5-7 months after the last infusion ${ }^{68}$.

How to manage multiple sclerosis/neuromyelitis optica spectrum disorder patients infected with coronavirus disease 2019

Patients with severe COVID-19 are susceptible to developing neurological complications, including acute cerebrovascular diseases, impaired consciousness, seizures, encephalopathy, and skeletal muscle injury. These complications could appear after respiratory symptoms and may be mediated by exacerbated immunological response. Immune damage and prothrombotic states associated with cytokine storm in COVID-19 might explain some neurological symptoms. In fact, it may be responsible for activating glial cells with subsequent demyelination. Furthermore, anecdotal cases of CNS demyelinating events after SARS-CoV-2 infection have been described ${ }^{69,70}$. Whether SARS-CoV-2 is associated with post-infectious inflammatory demyelinating events is still under debate ${ }^{71}$.

Immunosuppressive therapies are being studied as cytokine storm inhibitors for the adjunctive treatment of severe cases of COVID-19 infection (e.g., fingolimod - clinical trial ClinicalTrials.gov, Identifier: NCT04280588). Interferons MS DMDs - have antiviral properties and are of research interest in this pandemic (ClinicalTrials.gov, Identifier: NCT04343768, NCT04350671). Also, drugs used to treat NMOSD are currentlybeing evaluated in confirmed COVID-19 infected patients with severe pneumonia and SARS: tocilizumab (ClinicalTrials.gov, Identifier: NCT04317092), eculizumab (ClinicalTrials.gov, Identifier: NCT04288713), and intravenous methylprednisolone (ClinicalTrials.gov, Identifier: ChiCTR2000029386). However, the theoretical protective effects of MS/NMOSD DMDs for COVID-19 infections remain to be proven. Until further information is available, we suggest stopping DMDs during severe SARS-CoV-2 infection. In moderate and mild cases, DMD discontinuation should be individualized according to the aforementioned drug-safety profiles, patient's age, and other comorbidities. At this time, any drug that may interfere with immune response cannot be considered completely safe in a symptomatic patient.

Accordingly, MS/NMOSD patients infected with SARSCoV-2 should be treated following updated COVID-19 guidelines. In fact, current management of COVID-19 is supportive. Since potential treatment benefits of antivirals are not evidence-based (e.g., chloroquine derivatives or remdesivir) and data regarding interactions with DMDs are lacking, we do not recommend their use.

If the patient stops taking a DMD during COVID-19 infection, its reintroduction should be carefully planned according to MS/NMOSD activity, patient's age, and previously used drugs. Moreover, COVID-19 infection severity should be observed since it is related to viremia length. The literature has reported that after 10 days of symptom onset, $90 \%$ of previously positive nasopharyngeal RT-PCR in mild infections became negative, while the more severe ones remained positive ${ }^{72}$. In addition, immunosuppression may prolong the viremic period even further. At the same time, delaying the reintroduction of DMDs may increase the chance of relapses or even rebound (in case of prior natalizumab or fingolimod use). Hence, we recommend reintroducing DMDs 4 to 8 weeks after SARS-CoV-2 infection and encourage neurologists to consult with infectious disease specialists aiming to confirm viral clearance for prompt immunosuppression. 


\section{CONCLUSION}

The current COVID-19 pandemic is challenging the way we traditionally treat and monitor patients with CNS demyelinating diseases. At this moment, there is no evidence that infected MS or NMOSD patients present a higher risk of developing severe COVID-19. Nonetheless, caution and vigilance are necessary, as these patients are frequently immunosuppressed. In addition, their management requires adaptation during the pandemic in order to prevent SARS-CoV-2 infection whilst maintaining treatment safety and efficacy.

Suggested strategies for MS and NMOSD management during the pandemic are:

- Social distancing and using telemedicine.

- Avoiding treatment of mild relapse and using equivalent doses of oral steroids to treat MS relapses.

- Preference for drugs associated with lower infection risk (interferons, glatiramer, teriflunomide, and natalizumab) and extended-interval dosing of natalizumab, when safe.
- Postponing MS induction-treatment.

- Maintaining NMOSD preventive treatment.

- Wider interval between laboratory testing/imaging and using telemedicine to check results, when reasonable.

In the future, case series of MS/NMOSD patients infected with COVID-19 will help us define the best management strategies. For the time being, we rely on expert experience and counsel. Following the example of other centers ${ }^{73}$, we share our current strategies for patient care during the pandemic, hoping they will aid clinicians in our country.

\section{ACKNOWLEDGEMENT}

We would like to thank Prof. Dr. Gavin Giovannoni, a worldwide-known expert in MS, for kindly allowing us to adapt a table present on his website "MS Selfie" for Table 1 (available from: https://sites.google.com/giovannoni.net/ clinicspeak-dmt/home).

\section{References}

1. World Health Organization. Emergencies preparedness, response. Pneumonia of unknown cause in China. WHO. 2020. Available from: <https://www.who.int/csr/don/05-january-2020-pneumonia-ofunkown-cause-china/en/>.

2. Hoffmann M, Kleine-Weber H, Schroeder S, Krüger N, Herrler T, Erichsen S, et al. SARS-CoV-2 cell entry depends on ACE2 and TMPRSS2 and is blocked by a clinically proven protease inhibitor. Cell. 2020 Apr;181(2):271-80.e8. https://doi.org/10.1016/j.cell.2020.02.052

3. Xia H, Lazartigues E. Angiotensin-converting enzyme 2 in the brain: Properties and future directions. J Neurochem. 2008 Dec;107(6):1482-94. https://doi.org/10.1111/j.14714159.2008.05723.x

4. Thompson AJ, Banwell BL, Barkhof F, Carroll WM, Coetzee T, Comi G, et al. Diagnosis of multiple sclerosis: 2017 revisions of the McDonald criteria. Lancet Neurol. 2018 Feb;17(2):162-73. https://doi. org/10.1016/S1474-4422(17)30470-2

5. Kennedy PM. Impact of delayed diagnosis and treatment in clinically isolated syndrome and multiple sclerosis. J Neurosci Nurs. 2013 Dec;45(6 Suppl. 1):S3-13. https://doi.org/10.1097/ JNN.0000000000000021

6. Wingerchuk DM, Banwell B, Bennett JL, Cabre P, Carroll W, Chitnis T, et al. International consensus diagnostic criteria for neuromyelitis optica spectrum disorders. Neurology. 2015 Jul;85(2):177-89. https:// doi.org/10.1212/WNL.0000000000001729

7. Lennon PVA, Wingerchuk DM, Kryzer TJ, Pittock SJ, Lucchinetti CF, Fujihara K, et al. A serum autoantibody marker of neuromyelitis optica: Distinction from multiple sclerosis. Lancet. 2004 Dec;364(9451):210612. https://doi.org/10.1016/S0140-6736(04)17551-X

8. dos Passos GR, Oliveira LM, da Costa BK, Apostolos-Pereira SL, Callegaro D, Fujihara K, et al. MOG-IgG-associated optic neuritis, encephalitis, and myelitis: lessons learned from neuromyelitis optica spectrum disorder. Front Neurol. 2018 Apr;9:217. https://doi. org/10.3389/fneur.2018.00217

9. Papais-Alvarenga RM, Vasconcelos CCF, Carra A, Castillo ISd, Florentin S, Diaz de Bedoya FH, et al. Central nervous system idiopathic inflammatory demyelinating disorders in South Americans: a descriptive, multicenter, cross-sectional study. PLoS One. 2015 Jul;10(7):1-20. https://doi.org/10.1371/journal. pone. 0127757

10. Carrá A, J S, Macías-Islas M. COVID-19 en pacientes con esclerosis múltiple. Recomendaciones Latinoameticanas \& Sharing Initiative. Lat Am Comm Treat Res Mult Sclerosis-Lact. 2020;(1):1-22. http://www.lactrimsweb.org/wp-content/uploads/2020/04/ RECOMENDAÇÕES-GERAIS-DA-AMÉRICA-LATINA-PARAPACIENTES-E-CUIDADORES-002.pdf Acessed 11/05/2020

11. Pitombeira M, Paternò R, Braga N, Passos G, Callegaro D, LanaPeixoto M, et al. $2^{\circ}$ Comunicado BCTRIMS: Epidemia do Coronavírus (COVID-19). 2020. Available from: <https://www.bctrims.org.br/ wp-content/uploads/2020/03/20-Comunicado-BCTRIMS-Epidemiado-Coronav\%C3\%ADrus-COVID-19-INFORMA\%C3\%87\%C3\%95ESAOS-PACIENTES.pdf $>$.

12. Yeroushalmi S, Maloni H, Costello K, Wallin MT. Telemedicine and multiple sclerosis: a comprehensive literature review. J Telemed Telecare. 2019 May;1357633X19840097. https://doi. org/10.1177/1357633X19840097

13. Enquanto EE, Batalha DA, Ao DEC, Da C. ATO ADMINISTRATIVO ( AA) São Paulo, 17 de abril de 2020. Ref. AA Número 03 / 2020 Assunto : Teleneuroexame. 2020;(11). https://www.abneuro.org.br/post/atoadministrativo-aa-teleneuroexame. Acessed 11/05/2020

14. Milea D, Najjar RP, Jiang Z, Ting D, Vasseneix C, Xu X, et al. Artificial intelligence to detect papilledema from ocular fundus photographs. N Engl J Med. 2020 Apr;382:1687-95. https://doi.org/10.1056/ NEJMoa1917130

15. Zanin L, Saraceno G, Panciani PP, Renisi G, Signorini L, Migliorati K, et al. SARS-CoV-2 can induce brain and spine demyelinating lesions. Acta Neurochir (Wien). 2020 May:1-4. [Epub ahead of print]. https:// doi.org/10.1007/s00701-020-04374-X

16. Beck RW, Cleary PA, Anderson MMJ, Keltner JL, Shults WT, Kaufman DI, et al. A randomized, controlled trial of corticosteroids in the treatment of acute optic neuritis. N Engl J Med. 1992 Feb;326(9):581-8. https://doi.org/10.1056/NEJM199202273260901 
17. Lattanzi S, Cagnetti C, Danni M, Provinciali L, Silvestrini M. Oral and intravenous steroids for multiple sclerosis relapse: a systematic review and meta-analysis. J Neurol. 2017 May;264(8):1697-704. https://doi.org/10.1007/s00415-017-8505-0

18. Le Page E, Veillard D, Laplaud DA, Hamonic S, Wardi R, Lebrun C, et al. Oral versus intravenous high-dose methylprednisolone for treatment of relapses in patients with multiple sclerosis (COPOUSEP): A randomised, controlled, double-blind, non-inferiority trial. Lancet. 2015 Sep;386(9997):974-81. https://doi.org/10.1016/S01406736(15)61137-0

19. Elovaara I, Kuusisto H, Wu X, Rinta S, Dastidar P, Reipert B. Intravenous immunoglobulins are a therapeutic option in the treatment of multiple sclerosis relapse. Clin Neuropharmacol. 2011 Mar;34(2):84-9. https://doi.org/10.1097/wnf.0b013e31820a17f3

20. Abboud H, Petrak A, Mealy M, Sasidharan S, Siddique L, Levy M. Treatment of acute relapses in neuromyelitis optica: steroids alone versus steroids plus plasma exchange. Mult Scler. 2016 Apr;22(2):85192. https://doi.org/10.1177/1352458515581438

21. Elsone L, Panicker J, Mutch K, Boggild M, Appleton R, Jacob A. Role of intravenous immunoglobulin in the treatment of acute relapses of neuromyelitis optica: experience in 10 patients. Mult Scler. 2014 Aug;20(4):501-4. https://doi.org/10.1177/1352458513495938

22. Shosha E, Dubey D, Palace J, Nakashima I, Jacob A, Fujihara K, et al. Area postrema syndrome: Frequency, criteria, and severity in AQP4IgG-positive NMOSD. Neurology. 2018 Oct;91(17):E1642-51. https:// doi.org/10.1212/WNL.0000000000006392

23. Oliveira LM, Apóstolos-Pereira SL, Pitombeira MS, Bruel Torretta PH, Callegaro D, Sato DK. Persistent MOG-IgG positivity is a predictor of recurrence in MOG-IgG-associated optic neuritis, encephalitis and myelitis. Mult Scler. 2019 Dec;25(14):1907-14. https://doi. org/10.1177/1352458518811597

24. Harding K, Williams O, Willis M, Hrastelj J, Rimmer A, Joseph F, et al. Clinical outcomes of escalation vs early intensive disease-modifying therapy in patients with multiple sclerosis. JAMA Neurol. 2019 Feb;76(5):536-41. https://doi.org/10.1001/jamaneurol.2018.4905

25. Malpas CB, Ali Manouchehrinia A, Sharmin S, Roos I, Horakova D, Havrdova EK, et al. Early clinical markers of aggressive multiple sclerosis. medRxiv. 2019 Jan;19002063. https://doi. org/10.1101/19002063

26. Wijnands JMA, Zhu F, Kingwell E, Fisk JD, Evans C, Marrie RA, et al. Disease-modifying drugs for multiple sclerosis and infection risk: a cohort study. J Neurol Neurosurg Psychiatry. 2018;89(10):1050-6. https://doi.org/10.1136/jnnp-2017-317493

27. Epstein DJ, Dunn J, Deresinski S. Infectious complications of multiple sclerosis therapies: Implications for screening, prophylaxis, and management. Open Forum Infect Dis. 2018 Jul;5(8):1-8. https:// doi.org/10.1093/ofid/ofy174

28. The coronavirus and MS - global advice _ MS International Federation. https://www.msif.org/news/2020/02/10/thecoronavirus-and-ms-what-you-need-to-know/. Acessed 11/05/2020

29. Hughes R, Pedotti R, Koendgen H. COVID-19 in persons with multiple sclerosis treated with ocrelizumab - a pharmacovigilance case series. Mult Scler Relat Disord. 2020 May;42:102192. https://doi. org/10.1016/j.msard.2020.102192

30. Giovannoni G. Anti-CD20 immunosuppressive disease-modifying therapies and COVID-19. Mult Scler Relat Disord. 2020;41:102135. https://doi.org/10.1016/j.msard.2020.102135

31. Hatcher SE, Waubant E, Nourbakhsh B, Crabtree-Hartman E, Graves JS. Rebound syndrome in patients with multiple sclerosis after cessation of fingolimod treatment. JAMA Neurol. 2016 Jul;73(7):7904. https://doi.org/10.1001/jamaneurol.2016.0826

32. Sorensen PS, Koch-Henriksen N, Petersen T, Ravnborg M, Oturai A, Sellebjerg F. Recurrence or rebound of clinical relapses after discontinuation of natalizumab therapy in highly active MS patients. J Neurol. 2014 Apr;261(6):1170-7. https://doi.org/10.1007/s00415014-7325-8
33. Weideman AM, Tapia-Maltos MA, Johnson K, Greenwood M, Bielekova B. Meta-analysis of the age-dependent efficacy of multiple sclerosis treatments. Front Neurol. 2017 Nov;8:577. https:// doi.org/10.3389/fneur.2017.00577

34. Guillevin L, Pagnoux C, Karras A, Khouatra C, Aumaître O, Cohen $P$, et al. Rituximab versus azathioprine for maintenance in ANCAassociated vasculitis. N Engl J Med. 2014 Nov;371(19):1771-80. https://doi.org/10.1056/NEJMoa1404231

35. Durozard P, Rico A, Boutiere C, Maarouf A, Lacroix R, Cointe S, et al. Comparison of the response to rituximab between myelin oligodendrocyte glycoprotein and aquaporin-4 antibody diseases. Ann Neurol. 2020 Feb;87(2):256-66. https://doi.org/10.1002/ ana. 25648

36. Warny M, Helby J, Nordestgaard BG, Birgens H, Bojesen SE. Lymphopenia and risk of infection and infection-related death in 98,344 individuals from a prospective Danish population-based study. PLoS Med. 2018 Nov;15(11):1-22. https://doi.org/10.1371/ journal.pmed.1002685

37. Kappos L, Radue E-W, O'Connor P, Polman C, Hohlfeld R, Calabresi $P$, et al. A placebo-controlled trial of oral fingolimod in relapsing multiple sclerosis. N Engl J Med. 2010 Feb;362(5):387-401. https:// doi.org/10.1056/NEJMoa0909494

38. Francis G, Kappos L, O'Connor P, Collins W, Tang D, Mercier F, et al. Temporal profile of lymphocyte counts and relationship with infections with fingolimod therapy. Mult Scler. 2014 Apr;20(4):47180. https://doi.org/10.1177/1352458513500551

39. Comi G, Miller AE, Benamor M, Truffinet P, Poole EM, Freedman MS. Characterizing lymphocyte counts and infection rates with long-term teriflunomide treatment: pooled analysis of clinical trials. Mult Scler. 2019 Jun:1352458519851981. https://doi. org/10.1177/1352458519851981

40. Bomprezzi R. Dimethyl fumarate in the treatment of relapsingremitting multiple sclerosis: An overview. Ther Adv Neurol Disord. 2015 Jan;8(1):20-30. https://doi.org/10.1177/1756285614564152

41. Luna G, Alping P, Burman J, Fink K, Fogdell-Hahn A, Gunnarsson M, et al. Infection risks among patients with multiple sclerosis treated with fingolimod, natalizumab, rituximab, and injectable therapies. JAMA Neurol. 2020 Oct;77(2):184-91. https://doi.org/10.1001/ jamaneurol.2019.3365

42. Foley J, Carrillo-Infante C, Smith J, Evans K, Ho P-R, Lee L, et al. The 5-year Tysabri global observational program in safety (TYGRIS) study confirms the long-term safety profile of natalizumab treatment in multiple sclerosis. Mult Scler Relat Disord. 2020 Apr;39:101863. https://doi.org/10.1016/j.msard.2019.101863

43. Zhovtis Ryerson L, Frohman TC, Foley J, Kister I, Weinstock-Guttman B, Tornatore C, et al. Extended interval dosing of natalizumab in multiple sclerosis. J Neurol Neurosurg Psychiatry. 2016 Aug;87(8):885-9. https://doi.org/10.1136/jnnp-2015-312940

44. Zhovtis Ryerson L, Foley J, Chang I, Kister I, Cutter G, Metzger RR, et al. Risk of natalizumab-associated PML in patients with MS is reduced with extended interval dosing. Neurology. 2019 Oct;93(15):e1452-62. https://doi.org/10.1212/ WNL.0000000000008243

45. Barmettler S, Ong MS, Farmer JR, Choi H, Walter J. Association of immunoglobulin levels, infectious risk, and mortality with rituximab and hypogammaglobulinemia. JAMA Netw Open. 2018 Nov;1(7):e184169. https://doi.org/10.1001/ jamanetworkopen.2018.4169

46. Ellrichmann G, BolzJ, Peschke M, Duscha A, Hellwig K, Lee D-H, et al. Peripheral CD19 + B-cell counts and infusion intervals as a surrogate for long-term B-cell depleting therapy in multiple sclerosis and neuromyelitis optica/neuromyelitis optica spectrum disorders. J Neurol. 2019 Jan;266(1):57-67. https://doi.org/10.1007/s00415-018-9092-4

47. Sormani MP, Study I. An Italian programme for COVID-19 infection in multiple sclerosis. Lancet Neurol. 2020 Jun;19(6):481-2. https://doi. org/10.1016/S1474-4422(20)30147-2 
48. Giovannoni G, Comi G, Cook S, Rammohan K, Rieckmann P, Sørensen $P S$, et al. A placebo-controlled trial of oral cladribine for relapsing multiple sclerosis. N Engl J Med. 2010 Feb;362(5):416-26. https://doi. org/10.1056/NEJMoa0902533

49. Baker D, Herrod SS, Alvarez-Gonzalez C, Zalewski L, Albor C, Schmierer K. Both cladribine and alemtuzumab may effect MS via B-cell depletion. Neurol Neuroimmunol Neurolnflamm. 2017 Jul;4(4). https://doi.org/10.1212/NXI.0000000000000360

50. Kocsik AS, Klein DE, Liedke M, Kaunzner UW, Nealon NM, Gauthier SA, et al. Induction of disease remission with one cycle of alemtuzumab in relapsing-remitting MS. J Neurol. 2018 Apr;265(5):1226-9. https://doi.org/10.1007/s00415-018-8845-4

51. Kim SH, Huh SY, Lee SJ, Joung AR, Kim HJ. A 5-year follow-up of rituximab treatment in patients with neuromyelitis optica spectrum disorder. JAMA Neurol. 2013 Sep;70(9):1110-7. https://doi. org/10.1001/jamaneurol.2013.3071

52. Youssef J, Novosad SA, Winthrop KL. Infection risk and safety of corticosteroid use. Rheum Dis Clin North Am. 2016 Feb;42(1):157-76. https://doi.org/10.1016/j.rdc.2015.08.004

53. Singh G, Fries JF, Spitz P, Williams CA. Toxic effects of azathioprine in rheumatoid arthritis. A national post-marketing perspective. Arthritis Rheum. 1989 Jul;32(7):837-43.

54. Pollak R, Nishikawa RA, Mozes MF, Jonasson O. Azathioprineinduced leukopenia - clinical significance in renal transplantation. J Surg Res. 1980 Sep;29(3):258-64. https://doi.org/10.1016/00224804(80)90169-9

55. Mealy MA, Wingerchuk DM, Palace J, Greenberg BM, Levy M. Comparison of relapse and treatment failure rates among patients with neuromyelitis optica: multicenter study of treatment efficacy. JAMA Neurol. 2014 Mar;71(3):324-30. https://doi.org/10.1001/ jamaneurol.2013.5699

56. Subedi A, Magder LS, Petri M. Effect of mycophenolate mofetil on the white blood cell count and the frequency of infection in systemic lupus erythematosus. Rheumatol Int. 2015 Oct;35(10):1687-92. https://doi.org/10.1007/s00296-015-3265-6

57. Nogueras F, Espinosa MD, Mansilla A, Torres JT, Cabrera MA, MartínVivaldi R. Mycophenolate mofetil-induced neutropenia in liver transplantation. Transplant Proc. 2005 Apr;37(3):1509-11. https:// doi.org/10.1016/j.transproceed.2005.02.038

58. Cronstein BN. Molecular therapeutics: Methotrexate and its mechanism of action. Arthritis Rheum. 1996 Dec;39(12):1951-60. https://doi.org/10.1002/art.1780391203

59. Berkowitz RS, Goldstein DP, Bernstein MR. Ten years' experience with methotrexate and folinic acid as primary therapy for gestational trophoblastic disease. Gynecol Oncol. 1986 Jan;23(1):111-8. https:// doi.org/10.1016/0090-8258(86)90123-X

60. Gutierrez-Ureña S, Molina JF, García CO, Cuéllar ML, Espinoza LR. Pancytopenia secondary to methotrexate therapy in rheumatoid arthritis. Arthritis Rheum. 1996 Feb;39(2):272-6. https://doi. org/10.1002/art.1780390214
61. Saag KG, Gim GT, Patkar NM, Anuntiyo J, Finney C, Curtis JR, et al. American College of Rheumatology 2008 recommendations for the use of nonbiologic and biologic disease-modifying antirheumatic drugs in rheumatoid arthritis. Arthrit Care Res. 2008 Jun;59(6):76284. https://doi.org/10.1002/art.23721

62. Neurologia AB de. REDONE - PROJETO COVID19. https://www. abneuro.org.br/redone-projeto-covid-19.. Acessed 11/05/2020

63. Farez MF, Correale J, Armstrong MJ, Rae-Grant A, Gloss D, Donley $\mathrm{D}$, et al. Practice guideline update summary: Vaccine-preventable infections and immunization in multiple sclerosis: Report of the Guideline Development, Dissemination, and Implementation Subcommittee of the American Academy of Neurology. Neurology. 2019 Sep;93(13):584-94. https://doi.org/10.1212/WNL.0000000000008157

64. Child R, Schedule Al. 2020 4. 2020. https://www.cdc.gov/vaccines/ schedules/hcp/imz/child-adolescent.html Acessed 11/05/2020

65. SBIm. CALENDÁRIO DE VACINAÇÃO PACIENTES ESPECIAIS. https:// sbim.org.br/images/calendarios/calend-sbim-pacientes-especiais. pdf Acessed 11/05/2020

66. Vacinas DAS. CALENDÁRIO DE VACINAC̣ÃO SBIm ADULTO. 2021:2021. https://sbim.org.br/images/calendarios/calend-sbim-adulto.pdf. Acessed 11/05/2020

67. Lopez A, Mariette X, Bachelez H, Belotd A, Bonnottee B, Hachulla E, et al. Vaccination recommendations for the adult immunosuppressed patient: A systematic review and comprehensive field synopsis. J Autoimmun. 2017 Jun;80:10-27. https://doi. org/10.1016/j.jaut.2017.03.011

68. Rákóczi E, Szekanecz Z. Pneumococcal vaccination in autoimmune rheumatic diseases. RMD Open. 2017;3(2):e000484. https://doi. org/10.1136/rmdopen-2017-000484

69. Mao L, Wang M, Chen S, He Q, Chang J, Hong C, et al. Neurological manifestations of hospitalized patients with COVID-19 in Wuhan, China: a retrospective case series study. medRxiv. 2020 Feb;2020.02.22.20026500. https://doi. org/10.1101/2020.02.22.20026500

70. Zhao K, Huang J, Dai D, Feng Y, Liu L, Nie S. Acute myelitis after SARS-CoV-2 infection: a case report. medRxiv. 2020 Jan:2020.03.16.20035105. https://doi. org/10.1101/2020.03.16.20035105

71. Munhoz RP, Pedroso JL, Nascimento FA, Almeida SM, Barsottini OGP, Cardoso FEC, et al. Neurological complications in patients with SARSCoV-2 infection: a systematic review. Arq Neuro-Psiquiatr. 2020 May Jun;78(5): 290-300. http://dx.doi.org/10.1590/0004-282×20200051

72. Liu Y, Yan L-M, Wan L, Xiang T-X, Le A, Liu J-M, et al. Viral dynamics in mild and severe cases of COVID-19. Lancet Infect Dis. 2020 May;20(6):656-7. https://doi.org/10.1016/S1473-3099(20)30232-2

73. Brownlee W, Bourdette D, Broadley S, Killestein J, Ciccarelli O. Treating multiple sclerosis and neuromyelitis optica spectrum disorder during the COVID-19 pandemic. Neurology. 2020 Jun;92(22):10.1212/WNL.0000000000009507. https://doi. org/10.1212/wnl.0000000000009507 